\title{
Determination of the static modulus of elasticity of cement mortars in the early stage of ageing
}

\author{
Dalibor Kocab ${ }^{1, *}$, Romana Halamová ${ }^{1}$, and Barbara Kucharczyková ${ }^{1}$ \\ ${ }^{1}$ Brno University of Technology, Faculty of Civil Engineering, Veveři 331/95, 60200 Brno, Czech \\ Republic
}

\begin{abstract}
The paper deals with the influence of the composition of cementitious materials on the development of their modulus of elasticity in the early stage of ageing. The primary goal of the paper is to determine the static modulus of elasticity of cement mortars almost from the beginning of their setting. Four cement mortars were produced for the experiment. They differed only in the water/cement ratio and in the amount of plasticizer. All mortars were subjected to continuous measurement of the dynamic modulus of elasticity for 24 hours from the moment of their pouring into the moulds. The measurement involved the ultrasonic pulse velocity method. In addition, the static modulus of elasticity was determined at the mortar age of 24 hours. The results are presented in table and graphical forms.
\end{abstract}

\section{Introduction}

Today our advanced society places relatively high emphasis on the environmental aspect of industrial production, including the construction industry. In addition to costs, the amount of produced $\mathrm{CO}_{2}$ has recently become an important criterion too. In the case of constructions from concrete, its durability is being increasingly highlighted since it is one of the fundamental pillars of sustainability [1,2]. However, durability of concrete is generally very difficult to measure. There is no universal test or method that would unambiguously determine whether the given concrete is durable or not. It is also important to take into account the environment in which the assessed concrete is or will be located. Durability of concrete can therefore be assessed only indirectly on the basis of various tests of physical and mechanical characteristics. In addition, several criteria can be used to assess durability. In short, this matter is rather vague [3].

If cracks start to form in concrete, its durability may be reduced depending on the ambient conditions. Aggressive substances from the surrounding environment may spread through the cracks deeper into the concrete element and accelerate its damage. The sooner the cracks form after concreting, the higher the rate of degradation may be, since the concrete may not have aged sufficiently yet. One of the key factors that cause the formation and development of cracks in concrete is shrinkage [4]. Prominent shrinkage cracks, especially in the early stages of concrete aging, can be very dangerous. Their

\footnotetext{
*Corresponding author: dalibor.kocab@vutbr.cz
} 
formation may cause sever defects in the concrete structure soon after its completion. However, this condition can be prevented to a certain degree. There are a number of possibilities including optimization of the composition of the concrete, its proper curing and its sufficient reinforcement too [5]. In order to correctly design the reinforcement of a concrete element, it is useful to know, among other things, the internal stress that is induced in the concrete by shrinkage. Quantification of this stress requires the knowledge of the value of strain but also of the modulus of elasticity of the concrete. It is obvious, however, that this parameter changes over time and this paper thus focuses on determining its value in the first hours of ageing of cementitious material.

\section{Experiment}

The aim of the described experiment is to determine the value of the static modulus of elasticity of a cementitious material during the first 24 hours of its ageing. It is logically not possible to conduct the static test in the first hours after production and use the results to determine the modulus of elasticity of the cementitious material. Consequently, a non-destructive measurement method was employed, namely the ultrasonic pulse velocity method, whose output is the dynamic modulus of elasticity. Based on the results of the NDT measurement and the static test at the age of 24 hours, the development of the static modulus of elasticity at this stage of ageing of the cementitious material was calculated.

\subsection{Material and test specimens}

Four types of cement mortar were produced for the experiment. The initial design of the composition of the mortar is based on the standard EN 196-1 [6]. The production of the mortars employed standardised silica sand CEN with the maximum nominal grain size of $2 \mathrm{~mm}$ (according to standard [6]), cement CEM I $42.5 \mathrm{R}$ from the cement plant Mokrá (Czech Republic) and drinking water. The differences between the mortars lay in the water/cement ratio $(\mathrm{w} / \mathrm{c})$ and in the fact whether they contained the SVC 4035 plasticizer in the amount of $1 \%$ of the weight of the cement or not.

The mortar with the composition according to the standard [6] had the $\mathrm{w} / \mathrm{c}$ ratio equal to 0.50 - the amounts of the components were in the ratio $3: 1: 0.5$ (sand : cement : water). This mortar was designated M050. The second mortar differed only in the water/cement ratio, which was 0.40 - the amounts of the components were therefore in the ratio $3: 1: 0.4$ and the mortar was designated M040. The remaining two mortars had the same composition as the previously described mortars but contained also the plasticizer. These mortars were designated M050P and M040P.

Two types of test specimens were produced from each mortar. The first type was a test specimen in the shape of the Vicat ring. Its height is $40 \mathrm{~mm}$ and diameter changes gradually from $80 \mathrm{~mm}$ to $70 \mathrm{~mm}$. One test specimen in the shape of the Vicat ring was made from each mortar. The second type of the test specimens were beams with nominal dimensions of $40 \times 40 \times 160 \mathrm{~mm}$. Four beams were made from each mortar. In total, five specimens were made from each mortar for the purpose of the experiment.

\subsection{Test methods}

The specimen in the shape of the Vicat ring was used for the measurements of the individual mortars in the first 24 hours of aging. This specimen was subjected to continuous measurement almost from the moment of mixing the mortar using the Vikasonic ultrasonic device (Fig. 1). A Vicat ring-shaped cell was filled with mortar 
and the measurement was initiated within 2 minutes of the end of mixing. Mixing complied with the guidelines present in the standard EN 196-1. The Vikasonic device (more information e.g. in [7]) is designed primarily for the determination of setting times of binders, however, the measurement can also be applied to mortars or concrete with aggregate grain size up to $8 \mathrm{~mm}$. Its enormous advantage is the purely non-destructive character of the measurement - unlike measurements with the Vicat instrument - and the capability to measure the internal temperature of the test material. The measurement of the internal temperature is performed continuously along with the recording of the ultrasonic pulse transit time through the specimen.

All four $40 \times 40 \times 160 \mathrm{~mm}$ test beams were removed from the plastic moulds at the age of approximately 23.5 hours. After determining their dimensions and weight, they were used for the tests using the resonance method (Fig. 2 left). The measurement was conducted with the oscilloscope Handyscope HS4 with an acoustic emission sensor. The natural frequencies of the test specimens were assessed by software that is part of the oscilloscope and works on the fast Fourier transform principle. The measured natural frequencies can be used to calculate, among others, the Poisson's ratio $\mu_{c r}$ according to the standard ČSN 731372 [8]:

$$
\mu_{c r}=0,5 \cdot\left(k^{-1} \cdot f_{L}^{2} \cdot f_{t}^{-2}-2\right)
$$

where $k$ is a coefficient dependent on the shape of the cross-section of specimen, $f_{L}$ is the natural frequency of longitudinal vibration in $\mathrm{kHz}$ and $f_{t}$ is the natural frequency of torsional vibration in $\mathrm{kHz}$.

After the non-destructive measurement was terminated, one test beam was used to determine its compressive strength. The obtained value was used to determine the upper loading stress during the test of static modulus of elasticity $E_{c}$ according to the standard ISO 1920-10 [9] (Fig. 2 right). The upper loading stress is equal to $1 / 3$ of the expected compressive strength of the test specimens. The bottom stress is equal to $0.5 \mathrm{~N} / \mathrm{mm}^{2}$. The $E_{c}$ test was conducted in the DELTA 6-300 hydraulic testing machine. Strain of the test beams was continuously recorded during the test using strain transducer LD-DD1-2 (component of testing machine) and Spider8 data logger. All the tests were conducted 24 to 24.75 hours after mixing the mortars.

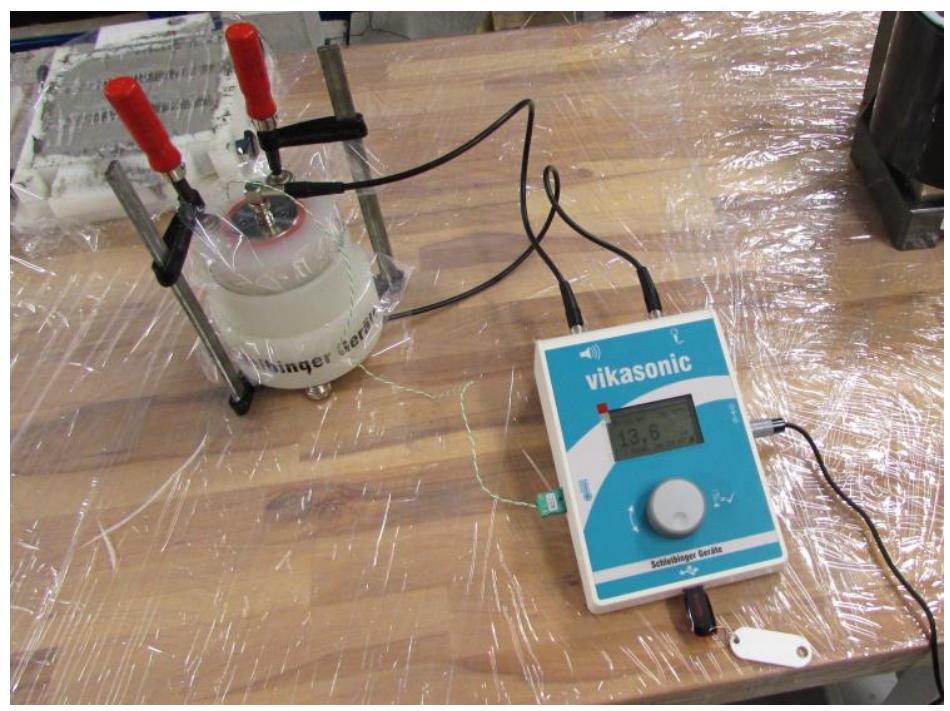

Fig. 1. Measurement using the ultrasonic pulse velocity method in the first 24 hours of ageing of the test mortars. 

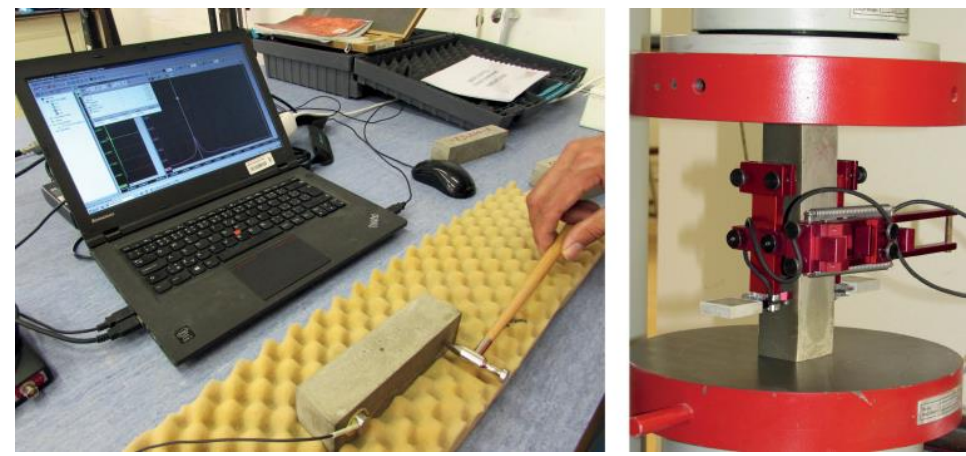

Fig. 2. Measurement of the natural frequencies using the resonance method (left) and the test of the static modulus of elasticity (right).

\section{Results}

The development of the temperature inside the mortar specimens in the first 24 hours of ageing is presented in Fig. 3. The continuous recording of the ultrasonic transit time through the material for all the mortars is presented in Fig. 4. Both records are the result of measurements with the Vikasonic instrument performed on the specimen in the shape of the Vicat ring from each mortar. The results clearly demonstrate that the plasticizing admixture delays the start of setting of the cementitious material. In the case of the transit time measured for the fresh mortar with plasticizer (MP040 and MP050), it can be observed that the material initially behaves like a liquid in terms of the ultrasonic pulse velocity method - the value of the transit time is around $30 \mu \mathrm{s}$ (see Fig. 4). When the main temperature peak starts to appear (see Fig. 3) the ultrasonic pulse velocity starts to rise. At this time the mortars start to set. There is therefore no reason to calculate the ultrasonic pulse velocity through the mortar before the time when the internal temperature starts to rise, see Fig. 5.

The dynamic modulus of elasticity was calculated in accordance with the standard ČSN 731371 [10]:

$$
E_{c u}=\rho \cdot v_{L}^{2} \cdot\left(1+\mu_{c r}\right) \cdot\left(1-2 \cdot \mu_{c r}\right) /\left(1-\mu_{c r}\right)
$$

where $E_{c u}$ is dynamic modulus of elasticity in $\mathrm{N} / \mathrm{mm}^{2}, \rho$ is density in $\mathrm{kg} / \mathrm{m}^{3}, v_{L}$ is ultrasonic pulse velocity in $\mathrm{km} / \mathrm{s}$ and $\mu_{c r}$ is dynamic Poisson's ratio.

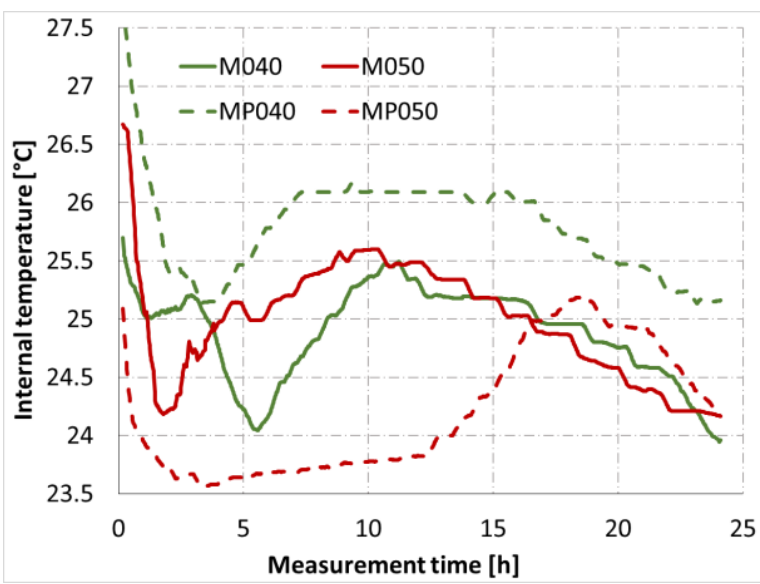

Fig. 3. Record of the internal temperature of the mortar specimens in the first 24 hours of ageing. 


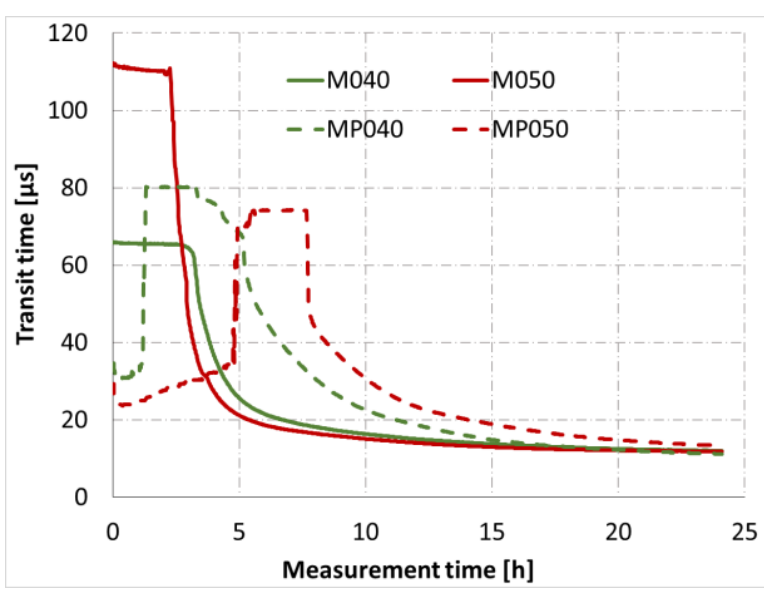

Fig. 4. Transit time of the ultrasonic pulse through the mortar in the first 24 hours of ageing.

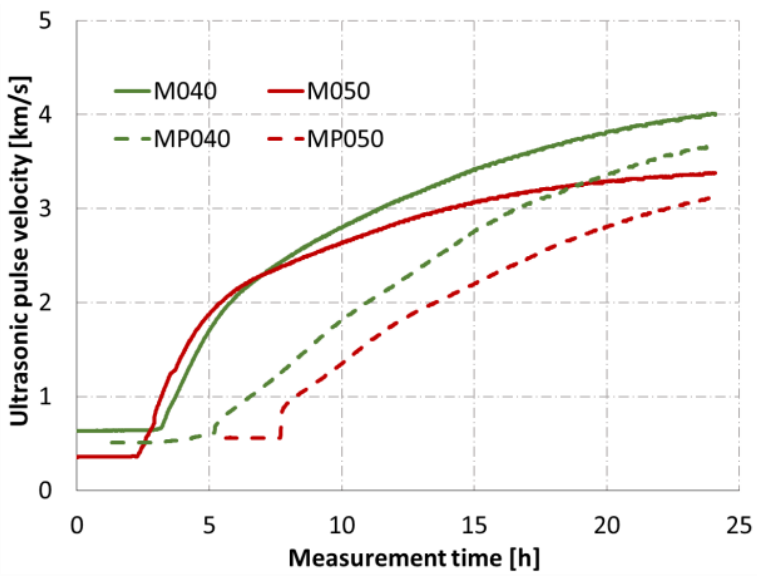

Fig. 5. Calculated velocity of the ultrasonic pulse through the mortar in the first 24 hours of ageing.

For the purposes of the calculation, the Poisson's ratio was considered to change in time - a value close to 0.5 immediately after the measurement was initiated and then determined by the resonance method at the age of 24 hours. More on the issue of the Poisson's ratio and the calculation of the dynamic modulus of elasticity in the first 24 hours of ageing of cementitious materials can be found in [11].

The last step was the calculation of the static modulus of elasticity from the dynamic modulus of elasticity. The coefficient $\eta_{u}$ was used for this purpose and expresses the ratio between the static and dynamic value of the modulus of elasticity. The coefficient $\eta_{u}$ was calculated from the results at the age of 24 hours (from Vikasonic measurement and from static test): $\eta_{u, M 040}=0.78, \eta_{u, M 050}=0.73, \eta_{u, M P 040}=0.73, \eta_{u, M P 050}=0.81$. The resulting development of the static modulus of elasticity of the individual mortars is presented in Fig. 6. Tab. 1 then shows the $E_{c}$ values of the individual mortars at four key times of the first day of their ageing. The results clearly show a significantly slower increase in the modulus of elasticity of the mortars with the plasticizer. 


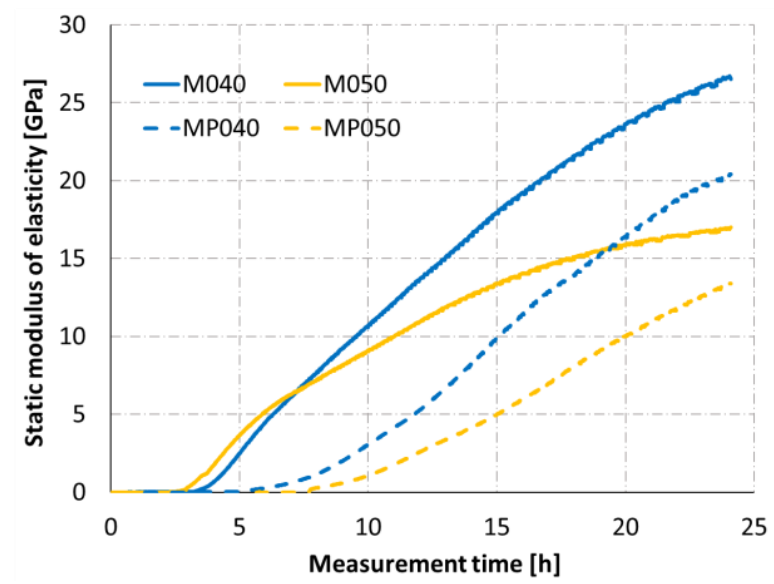

Fig. 6. Calculated static modulus of elasticity of the tested mortars in the first 24 hours of ageing.

Table 1. Calculated static modulus of elasticity of the mortars at the age of $6,12,18$ and 24 hours.

\begin{tabular}{|c|c|c|c|c|}
\hline Age [hours] & M040 & M050 & MP040 & MP050 \\
\hline 6 & 4.49 & 5.18 & 0.26 & 0.00 \\
\hline 12 & 13.69 & 10.96 & 5.27 & 2.58 \\
\hline 18 & 21.56 & 14.93 & 13.91 & 8.08 \\
\hline 24 & 26.64 & 16.96 & 20.39 & 13.38 \\
\hline
\end{tabular}

\section{Conclusion}

Based on the conducted measurements and calculations, it can be stated that the static modulus of elasticity of cement mortars (and consequently of concrete as well) can be easily and at the same time accurately determined already during the first 24 hours of ageing. The obtained values, however, are not calculated directly from the static tests. These are estimates of the static value of the modulus of elasticity based on the known development of the dynamic value of this parameter. The experiment demonstrated that although it is not possible to directly measure the static modulus of elasticity in the first hours after mixing the mortar, its value can be estimated with sufficient accuracy using the method described above.

This paper has been written as a part of project No. GA17-14302S, supported by the GAČR - Czech Science Foundation.

\section{References}

1. K. Hrabová, B. Teplý, P. Hájek, IOP Conference Series: Earth and Environmental Science 290 (2019)

2. fib Bulletin No. 28: Environmental Design (fib, Lausanne, 2004)

3. V. G. Papadakis, C. G. Vayenas, M. N. Fardis, Materials Journal, 88 (1991)

4. E. Holt, Cement and Concrete Research, 35 (2005) 
5. A. M. Soliman, M. L. Nehdi, Materials and Structures, 44 (2011)

6. EN 196-1 Methods of testing cement - Part 1: Determination of strength (CEN, Brussels, 2016)

7. www.schleibinger.com/cmsimple/en/?Setting_and_Maturity:Ultrasonic_Setting_Meas urement

8. ČSN 731372 Non-destructive testing of concrete - Testing of concrete by resonance method (ÚNMZ, Prague, 2012), in Czech

9. ISO 1920-10 Testing of concrete - Part 10: Determination of static modulus of elasticity (ISO, Geneva, 2010)

10. ČSN 731371 Non-destructive testing of concrete - Method of ultrasonic pulse testing of concrete (ÚNMZ, Prague, 2011), in Czech

11. R. Halamová, D. Kocáb, B. Kucharczyková, P. Misák, M. Alexa, Solid State Phenomena, 292 (2019) 